Available online at GSC Online Press Directory

GSC Biological and Pharmaceutical Sciences

e-ISSN: 2581-3250, CODEN (USA): GBPSC2

Journal homepage: https://www.gsconlinepress.com/journals/gscbps

(RESEARCH ARTICLE)

\title{
Assessment of calcium and phosphate levels among Sudanese children with malnutrition: A pilot study in Khartoum state
}

\author{
Ahmed RM 1, Yousif SO 2, Elhassan $\mathrm{SH}^{3}{ }^{3}$, Abubaker NE ${ }^{3}$ and Ibrahim MA ${ }^{3, *}$ \\ ${ }^{1}$ Department of Clinical Chemistry, Faculty of Medical Laboratory Sciences, Al- Neelain University, Khartoum, Sudan. \\ 2 Department of Clinical Laboratory Science, Faculty of Medical Applied Science, Jouf University, Alqurayat, Sadui Arabia. \\ ${ }^{3}$ Department of Clinical Chemistry, College of Medical Laboratory Science, Sudan University of Science and Technology, \\ Khartoum, Sudan.
}

Publication history: Received on 10 April 2020; revised on 28 April 2020; accepted on 29 April 2020

Article DOI: https://doi.org/10.30574/gscbps.2020.11.1.0095

\begin{abstract}
Malnutrition is a public health problem of significant importance in developing countries, it generally affects everyone in a community, but infants and children are the most vulnerable because of their high nutritional needs for growth and development. This study aimed to assess the levels of calcium and phosphate among Sudanese children with malnutrition. This case control study was conducted in Omdurman hospital in Khartoum, Sudan, during the period from April 2019 to May 2019. Fifty children with malnutrition (case) and 50 healthy children (control) were enrolled in this study; both groups were matched in age and sex. Blood samples were analyzed for calcium and phosphate levels using Mindray BS-200 automated analyzer. There was a significant decrease in phosphate level in malnourished children when compared with healthy children $(\mathrm{P}$-value $=0.00)$. According to the type of malnutrition, there were significant differences in mean of calcium level; marasmic children had lower mean level (7.1 mg/dL) compared with kwashiorkor and under-nutrition children $(9.4 \mathrm{mg} / \mathrm{dL})$. In addition, there was no correlation between serum calcium and phosphate levels with the duration of malnutrition. ( $\mathrm{r}=-0.071$. P-value $=0,624)(\mathrm{r}=00.077$. P-value $=0.593)$ respectively. In conclusion: Hypophosphatemia is a common finding among Sudanese malnourished children and marasmic children had decreased level of calcium when compared to other types of malnutrition. Accordingly, it is better to monitor serum phosphate level and other nutritional status within the recovery period.
\end{abstract}

Keywords: Malnutrition; Kwashiorkor; Marasmus; Calcium; Phosphorus and Sudanese children

\section{Introduction}

Although food is essential, it has often been lacking in the qualitative and quantitative point of view resulting in the occurrence of malnutrition. Indeed, malnutrition (under-nutrition, over-nutrition) is a public health problem of significant importance in developing countries [1]. It generally affects everyone in a community, but infants and children are the most vulnerable because of their high nutritional needs for growth and development [2]. Malnutrition is a medical condition caused by an improper or insufficient diet [3]. Technically, it is a category of disease that includes: under nutrition, obesity and overweight, and micronutrient deficiency among other [4]. However it is frequently used to mean just under nutrition from either inadequate calories or inadequate specific dietary component for whatever reason [5]. Malnutrition affects virtually every organ system during growth, adequate supplies of calcium and vitamin $\mathrm{D}$ are considered critically important to bone development and, if a child is going to fulfill their genetic potential for growth and peak bone mass, their diet must include a sufficient quantity of these nutrients [6]. It is necessary to investigate the causes of low calcium and vitamin D intake among people in growth phases, such as childhood and adolescence, to establish nutritional strategies to increase their dietary intake and to make it possible for populations

\footnotetext{
* Corresponding author: Ibrahim MA
} 
at nutritional risk to access foods rich in these nutrients [7]. Deficiencies of phosphorus, magnesium and other minerals are common in children with severe acute malnutrition. Feeding with diets rich in carbohydrate but with inadequate amount of phosphorus and magnesium can result in refeeding syndrome, characterized by hypophosphatemia and hypomagnesaemia, sometimes resulting in respiratory or circulatory failure or even death. Although concentrations of serum phosphate and magnesium may not adequately reflect body status, low levels may still be suggestive of inadequate intake [8,9]. The prevalence of malnutrition in Sudan was 33.0\% in urban areas and 40.5\% in rural areas [10]. Recent study in western region of Sudan, in New Halfa hospital reported that $16.3 \%$ of the admitted malnourished children have kwashiorkor and $83.7 \%$ have marasmus. Accordingly, the aim of this study was to assess the levels of calcium and phosphate among Sudanese children with malnutrition in Khartoum state and to find possible association between calcium and phosphate levels and duration of malnutrition.

\section{Material and methods}

This case control study was conducted in Omdurman hospital, Khartoum state, Sudan. The study was carried out from April to May 2019. The study was approved by scientific committee of Faculty of Medical Laboratory Science, Clinical Chemistry Department -Alneelain University. Fifty malnourished Sudanese children (case) and 50 apparently healthy children (control) were enrolled in this study. Gender and age were matched (ranged between 4 - 60 months). Malnourished children with bone diseases, parathyroid disease, chronic renal failure and any disorders that may affect the levels of phosphorus and calcium were excluded. After obtaining informed consent from the parents of participants, clinical data was collected by questionnaire then $5 \mathrm{~mL}$ of venous blood was collected in a plain container to obtain serum after centrifugation and samples were then refrigerated tell used.

The laboratory measurements of calcium and phosphate levels were carried out by using Mindray BS-200 automated analyzer. The accuracy and precision of results were measured using pathological and normal control sera. The data was analyzed by using Statistical Package for Social Sciences (SPSS) version 21. Values were expressed as percentage and Mean \pm SD. Independent T-test and one-way Anova analysis were used for comparison between groups and Pearson's correlation test was done to determine the association between study variables. P-value less than 0.05 was considered to be statistically significant.

\section{Results and discussion}

The majority of malnourished and healthy children were with age less than 24 month (70\%, 56\% respectively). 52\% of children were males and the rest were females in malnourished as well as in healthy children (Table 1). The findings of this study showed that there was a statistically significant decrease in the mean of phosphate level in malnourished children when compared to healthy children (Table 2). The majority of malnourished children were kwashiorkor 39 (78\%), moreover, there was significant decrease of calcium level regarding to the type of malnutrition, while phosphate revealed no significant difference (Table 3). The Correlation between serum calcium and phosphate levels with duration of malnutrition was displayed in figure 1.

Table 1 Baseline characteristic of study groups.

\begin{tabular}{|c|c|c|c|c|c|}
\hline & & \multicolumn{2}{|l|}{$\begin{array}{l}\text { Case } \\
\mathbf{N}=\mathbf{5 0}\end{array}$} & \multicolumn{2}{|l|}{$\begin{array}{l}\text { Control } \\
\mathbf{N}=\mathbf{5 0}\end{array}$} \\
\hline \multirow{3}{*}{ Age } & & Frequency & Percentage \% & Frequency & Percentage \% \\
\hline & $<24$ & 35 & $70 \%$ & 28 & $56 \%$ \\
\hline & $>24$ & 15 & $30 \%$ & 22 & $44 \%$ \\
\hline \multirow[t]{2}{*}{ Sex } & Male & 26 & $52 \%$ & 26 & $52 \%$ \\
\hline & Female & 24 & $48 \%$ & 24 & $48 \%$ \\
\hline
\end{tabular}


Table 2 Comparison of means of calcium and phosphate levels in study group

\begin{tabular}{llll}
\hline Variables & $\begin{array}{l}\text { Case } \\
\mathbf{N = 5 0}\end{array}$ & $\begin{array}{l}\text { Control } \\
\mathbf{N = 5 0}\end{array}$ & \multirow{2}{*}{ P-value } \\
\cline { 2 - 3 } & mean \pm SD & mean $\pm S D$ & \\
\hline Calcium $(\mathrm{mg} / \mathrm{dL})$ & $9.1 \pm 2.0$ & $10.0 \pm 1.9$ & 0.056 \\
Phosphate $(\mathrm{mg} / \mathrm{dL})$ & $4.0 \pm 1.1$ & $6.2 \pm 1.3$ & 0.000 \\
\hline
\end{tabular}

Table 3 Comparison of means of calcium and phosphate according to type of malnutrition.

\begin{tabular}{lllll}
\hline Variables & Kwashiorkor & Marasmus & Under-nutrition & \\
& $\mathbf{N ( \% )}$ & $\mathbf{N ( \% )}$ & $\mathbf{N ( \% )}$ & \multirow{2}{*}{ P-value } \\
& $\mathbf{3 9 ( 7 8 )}$ & $\mathbf{6 ( 1 2 )}$ & $\mathbf{5 ( 1 0 )}$ & \\
\cline { 2 - 4 } & mean $\pm \mathrm{SD}$ & mean $\pm \mathrm{SD}$ & mean $\pm \mathrm{SD}$ & 0.024 \\
\hline Calcium $(\mathrm{mg} / \mathrm{dL})$ & $9.4 \pm 1.8$ & $7.1 \pm 2.0$ & $9.4 \pm 2.5$ & 0.160 \\
\hline Phosphate $(\mathrm{mg} / \mathrm{dL})$ & $3.8 \pm 1.1$ & $4.7 \pm 1.2$ & $4.2 \pm 1.1$ & \\
\hline
\end{tabular}

A)

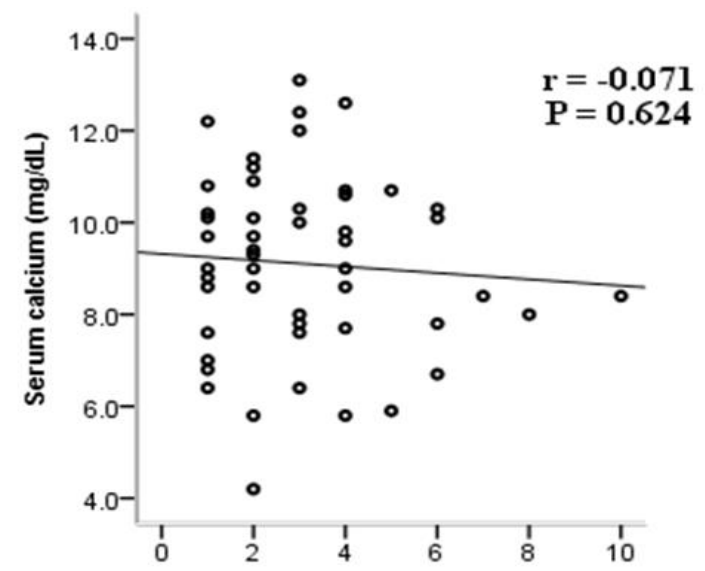

Duration of malnutrition (months)

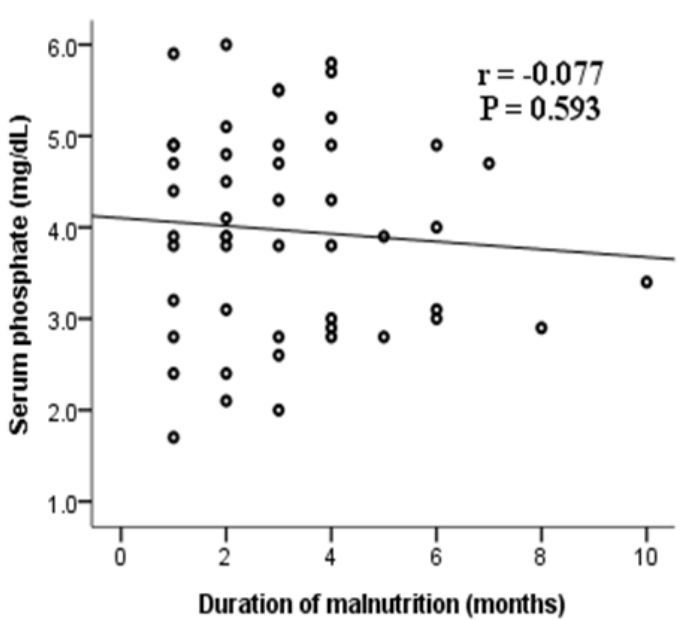

B)

Figure 1 Scatter dot regression of duration of malnutrition with A) serum calcium and B) serum phosphate.

Malnutrition is generally a nutritional problem that results from varying proportion of protein and calories lack in newborn and young children and it is a complicating factor for other illnesses in developing countries [11]. The findings of this study showed that, phosphate level was significantly lower in Sudanese malnourished children compared with healthy children (p-value=0.000). This finding agrees with Mahaman . et al., [11] Henry et al., [12] and Anne-Louise et al., [13] studies that reported, a significant decrease in the mean of phosphate level in malnourished children when compared with non-malnourished. The good explanation of this result may be due to inadequate intake [13]. Serum Calcium revealed no difference between study groups, the majority of children levels were within the normal range. This finding was counteracted by Mahaman et al., [11] and Noreen Samad et al., [14] studies that reported a decrease serum calcium level in malnourished children.

In the present study, there was a significant difference in calcium level regarding to the type of malnutrition, while phosphate level revealed no difference. Marasmic children had lower calcium level compared with kwashiorkor and under-nutrition children ( $p$ - value=0.024). Mahaman's study denoted that, the calcium and phosphate levels were not significantly different between types of malnutrition [11]. Inadequate feeding practices and low nutritional quality of meals might be an explanation of this result. In this study there were no correlations of serum calcium and phosphate 
with duration of malnutrition. This result is similar to another result which found no correlation between serum calcium, phosphate and duration of malnutrition $(r=-0.135$, $p$-value $=0.305)(r=-0.157, p$-value $=0.231)$ [15].

\section{Conclusion}

Sudanese malnourished children had decreased levels of phosphate in blood while children with marasmus had decreased levels of calcium when compared to other types of malnutrition. Accordingly, practical strategies are needed to address the dietary inadequacies and malnutrition of Sudanese children.

\section{Compliance with ethical standards}

\section{Acknowledgments}

The authors appreciate all who were contributed to the success of this study.

\section{Disclosure of conflict of interest}

All authors report no conflict of interest in this work.

\section{Statement of ethical approval}

The study was approved by scientific committee of Faculty of Medical Laboratory Science, Clinical Chemistry Department -Alneelain University.

\section{Statement of informed consent}

Informed consent was obtained from all individual participants included in the study.

\section{References}

[1] Amare B, Moges B, Fantahun B, Tafess K, Woldeyohannes, Yismaw G, Ayane T, Yabutani T, Mulu A, Ota F and Kassu K. (2012). Micronutrient levels and nutritional status of school children living in Northwest Ethiopia. Nutr. J, 11, 108.

[2] Asres G and Edelman A. (2011). Evaluation nutritionally des infants Ethiopians beta Israel: uneenquête transversal. Col. Med. Heal. Sci, 6(4), 171-176.

[3] Katsilambros N, Dimosthenopoulos C, Kontogianni MD, Manglara E and Poulia K. (2011). Clinical nutrition in practice, second edition. Wiley-Blackwel.

[4] World Health Organization. (2012). WHO, nutrition experts take action on malnutrition. Geneva: World Health Organization.

[5] World Health Organization and UNICEF. (2009). WHO child growth standard and the identification of sever acute malnutrition in infants and children.

[6] Salamoun M, Kizirian A, Tannous R, Nabulsi M, Choucair M, Deeb M, et al. (2005). Low calcium and vitamin D intake in healthy children and adolescents and their correlates. Eur J Clin Nutr, 59, 177-184.

[7] Stanga Z, Brunner A, Leuenberger M, Grimble RF, Shenkin A, Allison SP, et al. (2008). Nutrition in clinical practice-the refeeding syndrome: illustrative cases and guidelines for prevention and treatment. Eur J Clin Nutr, $62,687-694$.

[8] Maren R, Alemseged A and Christian R. (2016). Serum phosphate and magnesium in children recovering from sever acute under nutrition in Ethiopia. BMC Pediatric, 16, 178.

[9] World Health Organization. (2012). Programs and Projects. Global Database on Child Growth and malnutrition.

[10] Government of national Unit and Government of Southern Sudan. (2006). Sudan household health survey (SHHS).

[11] Mahaman YA, Akuyam SA, Danborno B, Galadima OM, Belemsigri M and Moussa SM. (2017). Evaluation of some Laboratory Parameters of Malnourished Children in Magaria District, Zinder, Niger Republic. Sub-Saharan African Journal of Medicin, 1(2), 77-81. 
[12] Henry WN, Kasolo J, Reuben KK, Agnes NK and Kiguli S. (2015). Serum vitamin D status in children with proteinenergy malnutrition admitted to a national referral hospital in Uganda. BMC Res Notes, 8, 418.

[13] Anne-Louise H., Tsinuel G., Maren JHR., Alemseged A., Christian R., Christian M., Kim FM., et al. (2016). Serum phosphate and magnesium in children recovering from severe acute undernutrition in Ethiopia: an observational study. BMC Pediatr, 16, 178.

[14] Noreen S, Sadia J, Amna L, Iqra Z and Rahat B. (2016). Serum analyte levels in children: relationship with malnutrition. International Journal of Food and Allied Sciences, 2(1), 30-35.

[15] Gasim AA and Abubaker NE. (2017). Evaluation of Plasma Levels of Calcium and Phosphate among Sudanese Children with Malnutrition in Khartoum State. M.Sc thesis, Sudan University of Science and Technology, Sudan, 45-47.

\section{How to cite this article}

Ahmed RM, Yousif SO, Elhassan SH, Abubaker NE and Ibrahim MA. (2020). Assessment of calcium and phosphate levels among Sudanese children with malnutrition: A pilot study in Khartoum state. GSC Biological and Pharmaceutical Sciences, 11(1), 207-211. 